\title{
Carretas y transporte terrestre bioceánico: la ruta Buenos Aires-Mendoza en el siglo XVIII*
}

PABLO LACOSTE**

Resumo: A carreta foi o principal meio de transporte terrestre na América colonial entre os séculos XVI e XIX. Uma das rotas mais utilizadas foi Buenos Aires-Mendoza, estabelecendo uma ligação entre os mercados do Atlântico e do Pacífico. Este artigo examina essas rotas, ao final do século XVIII, com base no processamento das viagens de 16.000 carretas. O tema será aprofundado em um segundo trabalho intitulado "Los troperos y los orígenes de la burguesía en el Cono Sur de América colonial" (previsto para o próximo número de Estudos Ibero-Americanos).

Abstract: The wagon was the main terrestrial facility in colonial America from the XVIth century until 1850. One of the most important routes to connect Atlantic and Pacific markets was Buenos Aires-Mendoza. This paper explores this route during the late XVIII century, based on 16.000 wagon trips. This subject will be further studied in the paper "Wagon drivers and the origin of the bourgeoisie in colonial America" (in the next edition of Estudos Ibero-Americanos).

Palavras chave: Carretas. Transporte terrestre colonial. Rotas bi-oceânicas.

Key words: Wagon. Colonial terrestrial transportation. Atlantic-Pacific routes.

Los troperos y sus carretas configuraron, junto a los arrieros y sus mulas, el sistema de transporte terrestre que articuló los mercados de América Latina durante más de 300 años. Desde la conquista española (siglo XVI), hasta la expansión del ferrocarril (segunda mitad del XIX), estos actores tuvieron a su cargo el transporte y el comercio en la región, y contribuyeron, en forma decisiva, a promover la agricultura, la ganadería, la minería y la industria artesanal. Su tarea fue complementaria del transporte marítimo y fluvial, que enlazaba los mercados locales con los puertos de

* Artículo elaborado en el marco del Proyecto "La viticultura en Cuyo y el Valle Central de Chile (1700-1850)", financiado por FONDECYT (Chile) no 1051109.

** Universidad de Talca, Chile. E.mail: placoste@utalca.cl

Estudos Ibero-Americanos. PUCRS, v. XXXI, n. 1, p. 7-34, junho 2005 
ultramar. Pero no fue menos importante, dada la necesidad de complementar las grandes rutas internacionales con los canales regionales de transporte y comunicaciones.

La relevancia de la carreta en el espacio latinoamericano se ha visto reflejada en las más diversas expresiones de la vida económica, social y cultural de la región. Un país ha elevado a la carreta al nivel de "símbolo nacional" (Costa Rica). ${ }^{1}$ En otras naciones se han realizado monumentos, esculturas y murales en honor a la carreta (Uruguay y Chile). ${ }^{2}$ La tradición de este medio de transporte es renovada constantemente en desfiles de carretas que se realizan en festivales populares, como los que ocurren cada año en Panamá. ${ }^{3}$ A ello podríamos añadir la apelación comercial a este tradicional medio de transporte, cuyo nombre es constantemente utilizado como marca o denominación de restaurantes, hoteles y posadas desde Argentina y Chile hasta Venezuela, México y EEUU, sobre todo los estados de origen hispánico como Florida y Nuevo México. La carreta es puesta allí, como símbolo de una tradición que se valora, aunque todavía no se comprenda muy bien por qué. Desde la literatura varios autores han colocado a la carreta en el centro de sus obras como René Marqués (Puerto Rico), Bruno Traven (México), Enrique Amorim (Uruguay), Juan Draghi Lucero y Ana Gándara (Argentina) y Luis Durand (Chile). En el campo de la música popular, la carreta se encuentra presente en canciones de muchos de los más difundidos cantores del Cono Sur, como Víctor Jara (Chile), Atahualpa Yupanqui y Buenaventura Luna (Argentina). ${ }^{4}$

1 República de Costa Rica. Poder Ejecutivo Nacional. Decreto 18197-C del 22 de marzo de 1988, firmado por el presidente de Costa Rica, Oscar Arias Sánchez.

2 Un buen ejemplo es el "Monumento a la carreta", obra del escultor José Belloni y emplazada en el parque Batlle de Montevideo (Uruguay). La escultura de las carretas fue inaugurada en 1934 y reconocida como Monumento Nacional de Uruguay el 8 de septiembre de 1976. Otro caso interesante es el parque escultórico "Cementerio de Carretas" en Putaendo (Chile), que alberga 44 esculturas y seis murales. Carta de Maribel Sánchez al autor, 22 de noviembre de 2004.

3 Podemos citar el "Desfile de carretas de bueyes" que cada año se realiza en el marco del "Festival Nacional de la Mejorana" en Guararé (Panamá). Durante este colorido evento "las calles del pequeño pueblo de Guararé están llenas de gente". Carta de Enrique A. Medina al autor, 19 de noviembre de 2004.

4 Gargiulo, Hebe et al. Buenaventura Luna, su vida y su canto. Buenos Aires: Imprenta del Senado de la Nación, 1985; Durand, Luis. La carreta de Juan Mardones. En: Durand, Luis. Siete cuentos. Santiago: Ercilla, 1997, p. 37-43; Lucero, Juan Draghi. Las mil y una noches argentinas. Edición original: Mendoza, edición de autor, 1940. Edición consultada: Buenos Aires: Colihue, 2001. Gándara, Ana. La carreta. Buenos Aires: EMECE, 1990; Traven, B. La carreta: novela. (primera edición en alemán, 1935; la segunda edición fue publicada por Aguilar en 1971). The carreta. Chicago: Ivan R. Dee, Inc., 1994; Amorim, Enrique. La carreta. Buenos Aires: Losada, 1952; Marqués, René. La carreta: drama en tres actos. Río Piedras: Editorial Cultural, 1963; Jara, Joan. Víctor Jara, un canto truncado. Barcelona: Ediciones B., 1999. 
La carreta surge entonces como un símbolo de la cultura latinoamericana, un referente identitario, un lazo con las raíces históricas. Así la ha captado la sensibilidad del artista y el creador. Pero también le corresponde al historiador hacer su trabajo, a partir de su propio método de investigación, es decir, con una base empírica clara y franca. En este plano, el primer paso es señalar que la carreta estuvo en el corazón de la actividad económica de América Latina durante más de tres siglos. Cronistas de los siglos XVIII y XIX observaron con interés a la carreta y lo expresaron desde distintos puntos de vista. El jesuita alemán Florian Paucke entregó detallados dibujos y acuarelas de las carretas rioplatenses. ${ }^{5}$ Concolorcorvo describió, comparativamente, las carretas tucumanas y mendocinas. ${ }^{6}$ El comerciante francés Julian Mellet destacó el papel que cupo a la carreta en el transporte de esclavos desde Buenos Aires a Mendoza, en el marco del tráfico que culminaba en Lima; en este sentido las carretas eran una suerte de prolongación terrestre de los barcos negreros.7

En el Cono Sur la carreta prestó servicios imponderables en el plano del transporte terrestre de carga. De Buenos Aires partían rutas carreteras hacia el norte (hasta Jujuy) y hacia el oeste (hasta Mendoza), por las cuales, a fines del siglo XVIII, circulaban anualmente miles de carretas. En la centuria siguiente se abrieron nuevas rutas. Entre ellas cabe destacar la ruta Buenos Aires-Tandil, abierta por el inmigrante español Ramón Santamarina; a mediados del siglo XIX, Santamaría conducía una tropa de 14 carretas con lana, cueros y plumas de Tandil a Buenos Aires y azúcar, sal, yerba mate y tabaco en el viaje de regreso. ${ }^{8}$ Las pampas argentinas eran un excelente escenario para las carretas, pero no el único. Del otro lado de la cordillera, en Chile, Bartolomé Flores comenzó a construir las primeras carretas en 1550; este sistema de transporte impulsó a las autoridades a construir algunos puentes, sobre todo en Santiago. ${ }^{9}$ Grandes

5 Paucke, Florián. Hacia allá y para acá: una estadía entre los indios mocobíes 17491767:Tucumán: Universidad Nacional de Tucumán, 1942.

6 Concolorcorvo El lazarillo de ciegos caminantes desde Buenos Aires hasta Lima. Edición original: Lima entre 1772 y 1774. Edición consultada: Buenos Aires, Espasa, 1946.

7 "En el momento de su partida de Buenos Aires para Lima [...] se separan ambos sexos se les amontona en grandes carretas cubiertas de cuero, tiradas cada una por ocho yuntas de bueyes, y cada una contiene 23 a 28 de esos esclavos. Estas carretas [...] en el camino de Buenos Aires a Mendoza, van algunas veces en número de cuarenta" (Mellet, Julián. Viajes por el interior de la América Meridional 1808-1820 [traducido de la segunda edición en francés de 1824; sin nombre del traductor]. Santiago: Editorial del Pacífico, 1959, p. 25-26).

8 Gándara, Ana. La carreta. Buenos Aires: EMECE, 1990, p. 40-48.

9 Villalobos, Sergio (dir.). Historia de la ingeniería en Chile. Santiago: Hachette, 1990, p. 48-49. 
inversiones se hicieron para fomentar el transporte en este tipo de vehículos. En 1795 se libró al servicio el camino de Santiago a Valparaíso, lo cual mejoró las condiciones de transporte; la circulación de carretas subió de 90 anuales en 1792 a 450 en 1799. Con el nuevo camino carretero, los troperos chilenos transportaban 25.000 toneladas de carga al año. ${ }^{10}$ Un siglo más tarde las carretas seguían prestando grandes servicios en Chile: entre 1904 y 1905 se construyó el camino carretero desde la estación ferroviaria de Graneros hasta la mina El Teniente; tenía una longitud de entre 50 y 55 kilómetros y ascendía a una altitud de 2.500 metros; durante siete meses, por este camino operaron casi ininterrumpidamente 250 carretas, traccionadas por cinco yuntas de animales en promedio, para trasladar 4.000 toneladas de equipo y todos los implementos necesarios para edificar la ciudad de Sewell e iniciar las actividades de la mina subterránea de cobre más grande del mundo.11

A pesar de su importancia en la economía regional, los troperos han ocupado un lugar muy secundario en la historiografía especializada. La obra de Serrera ha sido un interesante intento de entregar una mirada de conjunto sobre el transporte terrestre en América española, pero demuestra, a la vez, la escasez de trabajos específicos sobre cada región. ${ }^{12}$ Apoyado en este autor y en cronistas coloniales rioplatenses, Beck sostiene que la carreta se difundió por todo el espacio latinoamericano, pero muy particularmente en las pampas rioplatenses, sobre todo "entre Buenos Aires y las provincias del Litoral y del interior que hoy componen la República Argentina"; como fundamento alega que "la geografía llana de gran parte del país favoreció la difusión de la carreta". ${ }^{13}$ Se trata de una afirmación general, no apoyada en referentes empíricos concretos ni en cuadros comparativos. Las documentadas tesis doctorales de Pedro Santos Martínez y Edberto Oscar Acevedo sobre Mendoza y la Intendencia

10 Pinto, Sonia. Vías y medios de comunicación en Chile durante el siglo XVIII: el camino Santiago-Valparaíso y su tráfico. Santiago: Ediciones del Departamento de Estudios Humanísticos de la Universidad de Chile, 1976, p. 22-88.

11 Las carretas prestaron servicios en este camino en forma exclusiva hasta la inauguración de la línea ferroviaria (1911); a partir de entonces ambos sistemas de transporte convivieron, pero las carretas entraron en decadencia y dejaron de recorrer este trayecto en 1922. Baros Mansilla, María Celia. El teniente, los hombres del mineral 19051945.Santiago: Instituto de Ingenieros de Minas de Chile Núcleo O'Higgins, 1995, p. 151-157, 181-184.

12 Serrera, Ramón María. Tráfico terrestre y red vial en las Indias españolas. Barcelona: Lunverg, 1992.

13 Beck, Hugo Humberto. Distribución territorial de la conquista: red de urbanización y vías de comunicación. En: Academia Nacional de la Historia (ed.). Nueva Historia de la Nación Argentina - tomo 2: Periodo Español 1600-1810. Buenos Aires: Planeta, 1999 , p. 44. 
de Salta del Tucumán en el Virreinato del Río de la Plata, respectivamente, a pesar de poner mucho énfasis en los aspectos económicos, entregaron pocos datos cuantitativos sobre las carretas. Acevedo enfatiza la importancia de la fabricación de carretas en Tucumán, pues "dejaba una utilidad de \$70.000".14 En el caso de Martínez, por ejemplo, se aportan algunos pleitos interesantes de los carreteros, y las descripciones de Concolorcorvo, Haenke y Gillespie. 15

Entre los pocos estudios específicos dedicados a los caminos carreteros figuran los de Ricardo Donoso (1940) y Sonia Pinto (1976), centrados en la construcción del camino entre Santiago y Valparaíso a fines del siglo XVIII.16 Del otro lado de la cordillera de los Andes, el tema tampoco ha sido suficientemente investigado. La cuestión de los troperos y las carretas fue abordada por Zavalía Matienzo (1974) y Salas (1993). ${ }^{17}$ Ambos se apoyan mucho en las descripciones de Concolorcorvo, y agregan algunos pocos documentos de cosecha personal; el primero reproduce un juicio en torno a una tropa de nueve carretas (1819); el segundo presenta un panorama general del papel que cupo a la carreta en la Argentina tradicional, con algunos detalles interesantes sobre las costumbres de la época y el entorno social del transporte carretero. Fernández Latour de Botas (1998) tuvo la intención de estudiar los arrieros y troperos argentinos, para acercarse a los trabajos realizados sobre estos actores sociales en Perú y Brasil. Pero la autora no logró sustraerse a la fuerte succión del gaucho. $Y$ tras presentar el perfil de los arrieros y troperos peruanos y brasileros, con sus singulares características, llegó a afirmar que "en la campaña rioplatense, el protagonista de esa existencia fue el gaucho". ${ }^{18}$ Evidentemente, esta autora transitaba más cerca de la literatura que de la historia y por tal motivo, no logró escapar a la abrumadora hegemonía de la gauchesca. De todos modos, de estos autores surgen algunas conclusiones interesantes. Sobre todo porque

14 Acevedo, Edberto Oscar. La intendencia de Salta del Tucumán en el virreinato del Río de la Plata. Mendoza: Universidad Nacional de Cuyo, 1965, p. 275.

15 Martínez, Pedro Santos. Historia económica de Mendoza durante el virreinato. Edición original: Mendoza, FFyL, 1961. Edición consultada: Buenos Aires: Ciudad Argentina, 2000, p. 274-275 y 297-313.

16 Donoso, Ricardo. El marqués de Osorno. Santiago: Universidad de Chile, 1940, p. 227237; Pinto, Sonia. Vias y medios..., p. 24.

17 Zavalía Matienzo, Roberto, Las carretas tucumanas. Su importancia en la economía argentina. En: Investigaciones y Ensayos, $\mathrm{n}^{\circ}$ 17, Buenos Aires, julio-diciembre de 1974 pp. 243-268. Salas, Andrés Alberto. La Carreta. Todo es Historia, 315 (octubre 1993), p. 30-43; reeditado en: Luna, Félix. Lo mejor de Todo es Historia. Buenos Aires: Taurus, 2002, tomo 2, pp. 383-405.

18 Fernández Latour de Botas, Olga. Apuntes sobre "troperismo", arrieraje y sus equivalentes en el folklore y en la literatura de la Argentina. Investigaciones y Ensayos, 48 (enero-diciembre de 1998), p. 154. 
detectaron dos grandes polos de fabricación de carretas, uno en Tucumán y otro en Mendoza. Pero no se estudian las rutas concretas ni el volumen de carga transportado.

Las rutas de las carretas es otro tema sobre el cual se ha escrito más de lo que se ha investigado. Se ha estandarizado en la historiografía argentina una visión de acuerdo a la cual, las carretas habrían creado una red de integración entre las distintas regiones, hasta lograr un mercado interno integrado y bien articulado. Se habría constituido así una suerte de pasado idílico, el cual se habría roto con la implantación de los ferrocarriles. Estos pusieron en servicio grandes empresas que conectaron Buenos Aires con Córdoba y Tucumán por un lado, y Buenos Aires con Mendoza por otro; pero los ingleses nunca construyeron un ferrocarril de Tucumán a Mendoza. Este esquema habría obedecido a un perfil de colonia económica que los ingleses quisieron darle a la Argentina: el modelo de ferrocarrilembudo apuntaba a extraer las materias primas de la Argentina, rumbo al puerto, e introducir las manufacturas británicas, para destruir las industrias locales. ${ }^{19}$ De acuerdo a esta visión, la red ferroviaria vino a romper las anteriores rutas internas, vigentes en tiempos de las carretas, mediante las cuales se había logrado una mejor integración entre los distintos polos económicos de la actual Argentina. Esta estandarizada tesis se construyó en forma intuitiva, sin presentar mayores pruebas. Simplemente porque no se hicieron estudios empíricos de las rutas de las carretas.

De los dos grandes polos de transporte carretero del Virreinato del Río de la Plata, Tucumán y Mendoza, este artículo examina las rutas de las carretas que circulaban desde y hacia el segundo, es decir, Mendoza. Para alcanzar una base empírica amplia, se han considerado los registros de aduana, sobre todo los manuales de Cargo y Data. A partir de ellos ha sido posible elaborar una base de datos de más de 15.000 carretas. Para complementar los datos cuantitativos con la parte cualitativa de este mundo socioeconómico, se han relevado también los Protocolos de Escribanos para dar cuenta de operaciones de compra, venta, donación e hipoteca de carretas; así mismo, se han examinado cerca de 50 testamentos de troperos avecindados en Mendoza, con vistas a distinguir aspectos importantes de su vida: movilidad, social, redes de crédito, vínculo con otras actividades económicas (sobre todo la industria de la vid y el vino), entre otros datos. Como resultado se ha podido trazar un perfil bastante rico y detallado del tropero como sujeto histórico.

19 Scalabrini Ortiz, Raúl. Historia de los ferrocarriles argentinos. Primera edición: Buenos Aires, 1935. Edición consultada: Buenos Aires, Plus Ultra, 1958, p. 17-18. 
La base de operaciones considerada, como se ha dicho, es la ciudad de Mendoza. Esta fue la capital de la provincia de Cuyo del Reino de Chile durante más de dos siglos (1561-1776), y luego se incorporó al Virreinato del Río de la Plata (1776-1810), para integrar después, la República Argentina. Se va a estudiar la cantidad de carretas que entraron y salieron de Mendoza, la formación de las partidas, las rutas utilizadas, los puntos de origen y destino de las cargas, y el perfil de los empresarios troperos que las conducían. La posición estratégica de Mendoza en las rutas comerciales de la región contribuyó al desarrollo de los arrieros y troperos y con ellos, de una mentalidad proclive al surgimiento de la burguesía. Por esta ciudad pasaban los principales caminos que vinculaban los mercados de la Cuenca del Plata con el Reino de Chile. Por tal motivo, centenares de troperos de carretas y arrieros de mulas entraban y salían constantemente de la ciudad, lo cual la dotaba de un movimiento y una dinámica muy particular.

Los conceptos de tropero y carretero merecen un breve comentario. En Argentina y Uruguay se utiliza la noción de tropero para denominar al "conductor de tropas de carretas o de ganado". ${ }^{20}$ A su vez, el carretero puede ser tanto "el que hace carros y carretas" como "el que guía las caballerizas o los bueyes que tiran de tales vehículos". ${ }^{21}$ De ambas acepciones, en este trabajo se utiliza la segunda. Por lo tanto, no se estudia aquí a los fabricantes de carretas sino a los que las conducían a lo largo de las rutas de las pampas. En este sentido, el presente texto va a emplear las categorías de tropero y carretero como sinónimos.

\section{El movimiento de las carretas: una mirada general de corte cuantitativo}

Con sus valiosas cargas de vinos, yerba mate y esclavos, las carretas iban y venían de Buenos Aires a Mendoza durante toda la época colonial. Las carretas entrantes y salientes en los nueve años registrados en la Real Aduana de la capital de Cuyo hacia fines del siglo XVIII, llegaron a 15.209 unidades, distribuidas en 1.227 partidas, con un promedio de 12,39 carretas por partida (ver Cuadro I). El promedio anual fue de 1690 carretas. Cada día entraban o salían

20 Real Academia Española. Diccionario de la Lengua Española. Madrid: Real Academia Española (21 edición), 1992, p. 2, 2003; Academia Argentina de Letras. Diccionario del habla de los argentinos. Buenos Aires: Espasa, 2003, p. 549.

21 Real Academia Española. Diccionario de la Lengua Española. Madrid: Real Academia Española (21 edición), 1992, p. 1, 423. 
de Mendoza casi cinco carretas. Se trata de una cifra muy elevada, sobre todo si se tiene en cuenta que la población de Mendoza apenas alcanzaba a 10.000 habitantes a comienzos del siglo XIX. El movimiento de carretas llegaba a uno de cada seis habitantes al año. Es importante considerar también el impacto económico del servicio de transporte.

Las carretas entrantes superaban ampliamente a las salientes, siempre según la fuente señalada. En los nueve años registrados ingresaron a Mendoza 8.210 carretas y salieron 6.999. Quedó un saldo de 1.211 carretas. En cifras anualizadas, cada año entraban a Mendoza 912 carretas y salían de ella 777, lo cual dejaba un remanente de 135 carretas en la provincia. Ello se explica, fundamentalmente, por dos motivos. Por un lado, Mendoza exportaba sobre todo productos industriales, con alto valor agregado (vinos $\mathrm{y}$ aguardientes envasados en botijas de cerámica), en tanto que sus mayores importaciones eran productos primarios, de menor valor agregado (sobre todo yerba mate) juntamente con esclavos. Por otra parte, un importante volumen de estas cargas seguía camino a Chile, a lomo de mula, conducido por los arrieros. Ello significaba, junto con los lucrativos negocios, un volumen imponderable de dolor, sobre todo cuando la "carga" que cruzaba la cordillera eran seres humanos. Mellet describió este fenómeno en los siguientes términos:

Llegados (en las carretas) a Mendoza, (los esclavos) toman algunos días de reposo y se les hace en seguida continuar el viaje a Valparaíso pero de manera bien diferente. Se les monta a caballo o en mulas cuyas sillas muy chicas solo sirven para esta clase de transportes. Este nuevo cambio es para esos infelices una era de sufrimientos: como no están acostumbrados al caballo sufren toda clase de incomodidades y por poco vigorosa que sea la bestia que los conduce, al menor movimiento da con ellas en el suelo. Los que caen y se levantan para volver a montar, sufren a veces coces tan fuertes que a menudo quedan tendidos muertos sobre el campo. Esos accidentes son muy frecuentes y no se hace expedición alguna sin que haya algunos esclavos muertos o estropeados. Rudos sufrimientos los esperan en las cordilleras, acostumbrados a un clima excesivamente cálida y enteramente opuestos al que están obligados a atravesar, se sienten de tal modo transidos de frío al acercarse a esas montañas, que muchos de entre ellos quedan rígidos o dejan de existir cuando se les cría bien. 22

22 Mellet, Viajes..., p. 25-26. 
La precisa observación del comerciante francés no escatimaba consideraciones emocionales. Su sensibilidad le permitió advertir el impacto que podía causar en personas originarias de zonas tropicales, la travesía de la cordillera más alta del mundo fuera de Asia, muchas veces con nieve y temperaturas de $-14^{\circ}$ centígrados. Mellet fue contundente en sus afirmaciones:

A menos de estar falto de todo sentimiento humanitario, no se puede, sin estremecerse, dar una mirada a las desgracias que la avaricia hace sufrir a esas infortunadas criaturas cuyo único crimen es tener el color distinto del nuestro. Los horrorosos tormentos que se les hace experimentar, han excitado la justa indignación de muchos escritores sensibles y generosos [...]. Los horrores que he visto con mis propios ojos y de los cuales doy el detalle, se renuevan aún hoy en día muy a menudo. ${ }^{23}$

El dolor humano de los esclavos africanos en la cordillera de los Andes, a 4.000 metros de altitud, apunados, entumecidos de frío y agredidos por los capataces, fue una parte indispensable de todo el proceso lucrativo de las carretas. El superávit de bienes que Mendoza tenía en el tráfico de cargas carreteras, se compensaba con el déficit que experimentaba en el comercio de las recuas de mulas con destino a Chile.

La principal ruta que utilizaban las carretas enlazaba Mendoza con Buenos Aires. Sobre un total de 15.209 carretas registradas, 14.345 unieron esos dos puntos, lo cual representa el $94,43 \%$ de la muestra. Este dato es crucial porque demuestra que, un siglo antes de la inauguración del Ferrocarril Buenos Aires al Pacífico, la principal ruta comercial de la economía de Mendoza se hallaba justamente en Buenos Aires. Este era el principal mercado para los excedentes de la producción mendocina y, a la vez, el principal proveedor de la capital cuyana. En efecto, sobre un total de 8.210 carretas entrantes, de Buenos Aires provenían 7.726 $(94,10 \%) ;$ y de las 6.999 carretas salientes, hacia Buenos Aires fueron 6.619 (94,57\%). En términos anualizados, cada año entraban a Mendoza 65 partidas con 860 carretas de Buenos Aires y salían 55 partidas con 735 carretas cargadas con productos mendocinos, sobre todo vinos. Había, al menos, un servicio regular de transporte de cargas en tropas de carretas, con una frecuencia mensual, tanto de Mendoza a Buenos Aires como en sentido inverso.

23 Mellet, Viajes..., p. 26. 
La continuidad de este servicio de cargas permitió a los mendocinos poner en marcha su floreciente industria vitivinícola. Al tener un mercado asegurado, con un sistema de transporte confiable y regular de cargas, la clase dirigente de Mendoza se vio alentada a realizar avances en el campo de la industria de la vid y el vino, la cual requiere de muchos años de continuidad para la amortización de las inversiones. Ello permitió que se multiplicaran las fábricas de botijas, la superficie cultivada con viñedos, las instalaciones y el equipamiento para elaborar el vino, con lagares y vasija vinaria cada vez más modernos y de calidad. Ya en el siglo XVIII, el mercado de Buenos Aires fue plenamente funcional al desarrollo de la industria y de la burguesía vitivinícola de Mendoza.

El servicio carretero consolidó también el tráfico de esclavos. Mediante el empleo de este medio de transporte, los afroamericanos llegaron a ser un cuarto de la población de Mendoza, donde vivían cerca de 2.500 esclavos a comienzos del siglo XIX; también fue importante la cantidad de esclavos que, desde Mendoza, pasaron a Chile, donde para esa época vivían 12.000 afroamericanos. A ello hay que añadir una cantidad todavía mayor de esclavos que llegaron finalmente a Lima, el principal mercado negrero de la costa del Pacífico Sur de América.

Desde el punto de vista de las rutas más empleadas, era muy notable el predominio del tráfico entre Mendoza y Buenos Aires; desde esta perspectiva, los servicios entre Mendoza y otros puntos eran marginales. De todos modos, conviene describir cuáles eran y qué magnitud tenían. En total, existían otros diez puntos de origen y destino para el comercio de Mendoza, que se agrupan en tres zonas geográficas: litoral, noroeste y otros. Examinaremos a continuación las principales características de cada uno de ellos.

La zona del Litoral configuró la segunda en importancia para el comercio carretero de Mendoza. Abarcaba cinco puntos emplazados junto a la ribera del río Paraná: la ciudad de Santa Fe, la localidad de Las Tunas (ubicada muy cerca de la anterior), San Nicolás de los Arroyos, Paraná y Capilla del Rosario (localidad que luego originó la actual ciudad de Rosario). El comercio de Mendoza con esta zona ascendió a 92 partidas y 583 carretas. Las partidas llevaban pocas carretas: el promedio era de 6,3 unidades por caravana, es decir, la mitad que en la ruta de Buenos Aires. El flujo hacia Mendoza era casi el doble que a la inversa: 371 contra 212 carretas. Ello representaba el 3,07\% de las unidades movilizadas por los troperos en el comercio de Mendoza. En términos anualizados, puede decirse que cada año entraban a Mendoza menos 
de seis partidas con 41 carretas del Litoral, y salían con este destino cuatro partidas con 23 carretas. Evidentemente, no existía un servicio regular de cargas, sino con intervalos de tiempo muy amplios. Dentro de la zona del Litoral, cuatro quintas partes de las cargas circulaban desde o hacia la ciudad de Santa Fe. Casi la totalidad del quinto restante se orientaba a San Nicolás de los Arroyos, mientras Paraná, Las Tunas y Capilla del Rosario sólo fueron destinos eventuales para las cargas de Mendoza.

La zona del Centro y Noroeste fue la tercera en importancia para el comercio de Mendoza. Allí se hallaron los puntos de origen y destino de 29 partidas con 219 carretas, lo cual representaba el $1,43 \%$ del total de unidades movidas por el comercio de Mendoza. Eran partidas muy pequeñas: 7,55 carretas por viaje; estaban muy cerca de las caravanas del Litoral, y muy lejos de las grandes partidas que iban de Mendoza a Buenos Aires. El comercio con la zona del Centro y Noroeste era virtualmente imperceptible en la economía de Mendoza. Si se examinan los datos por promedios anuales, se advierte que cada año ingresaban a la capital cuyana 1,6 partidas con 10 carretas desde aquella región; y salían con ese rumbo 1,5 partidas con 14 carretas. No existían servicios regulares ni lazos comerciales permanentes entre Mendoza y estos mercados.

Las otras ciudades cuyanas, en cambio, sólo tuvieron un escaso comercio carretero con Mendoza. En los nueve años registrados, entre Mendoza y San Luis circularon 16 partidas de carretas, ocho entrantes y ocho salientes. No llegó a existir un viaje de promedio anual. Además, estas partidas llevaban muy pocas carretas, con un promedio de apenas 3,6 unidades por viaje. La situación era todavía más pobre en el comercio entre Mendoza y San Juan: en todo el periodo estudiado no se registró una sola carreta que haya transportado cargas entre ambas ciudades. El despertar de la producción minera de La Carolina, en las montañas del norte de San Luis, tampoco alteró esta situación; ni el oro ni la plata que salían de allí, ni el azogue o las provisiones y alimentos necesarios para los mineros de esta zona, contribuyeron a generar tráfico carretero con Mendoza. Este comercio existía pero como era de dimensiones acotadas, se realizaba exclusivamente a través de los arrieros y sus mulas, tal como se estudia en otra parte. ${ }^{24}$

24 Lacoste, Pablo. El arriero y el transporte terrestre en el Cono Sur, Mendoza, 17801800 (aceptado para publicación en Revista de Indias, volumen 65, $\mathrm{n}^{-} 35$, Madrid, 2005). 


\section{Cuadro I}

Comercio de Carretas entre Mendoza y las provincias del Plata

(Fines del siglo XVIII)

\begin{tabular}{|c|c|c|c|c|c|c|c|c|c|c|}
\hline \multirow{2}{*}{$R \cup T A$} & \multicolumn{2}{|c|}{$\begin{array}{l}\text { Entrada a } \\
\text { Mendoza }\end{array}$} & \multicolumn{2}{|c|}{$\begin{array}{l}\text { Salida de } \\
\text { Mendoza }\end{array}$} & \multicolumn{2}{|c|}{$\begin{array}{l}\text { Diferencia } \\
\text { (E-S) }\end{array}$} & \multicolumn{2}{|c|}{ Sumatoria $(E+S)$} & \multirow{2}{*}{$\begin{array}{c}\text { Prom } \\
C / P\end{array}$} & \multirow[t]{2}{*}{$\% \mathrm{P}$} \\
\hline & $P$ & C & $P$ & C & $\mathrm{P}$ & C & $P$ & C & & \\
\hline Buenos Aires & 590 & 7.726 & 499 & 6.619 & 91 & 1.107 & 1.089 & 14.345 & 13,17 & 94,1 \\
\hline Subtotal Baires & 590 & 7.726 & 499 & 6.619 & 91 & 1.107 & 1.089 & 14.345 & 13,17 & 94,1 \\
\hline Santa Fe & 36 & 310 & 24 & 158 & 12 & 152 & 60 & 468 & 7,80 & 3,07 \\
\hline Las Tunas & 0 & 0 & 1 & 3 & -1 & -3 & 1 & 3 & 3,00 & 0,01 \\
\hline $\begin{array}{l}\text { San Nicolás } \\
\text { de los Arroyos }\end{array}$ & 17 & 61 & 12 & 44 & 5 & 17 & 29 & 105 & 3,62 & 0,69 \\
\hline Capilla del Rosario & 0 & 0 & 1 & 2 & -1 & -2 & 1 & 2 & 2,00 & 0,01 \\
\hline Paraná & 0 & 0 & 1 & 5 & -1 & -5 & 1 & 5 & 5,00 & 0,03 \\
\hline Subtotal Litoral & 53 & 371 & 39 & 212 & 16 & 159 & 92 & 583 & 6,33 & 3,83 \\
\hline Córdoba & 13 & 52 & 13 & 110 & 0 & -52 & 26 & 162 & 6,23 & 1,06 \\
\hline Tucumán & 2 & 41 & 0 & 0 & 2 & 41 & 2 & 41 & 20,1 & 0,26 \\
\hline Santiago del Estero & 0 & 0 & 1 & 16 & -1 & -16 & 1 & 16 & 16 & 0,10 \\
\hline Subtotal NOA & 15 & 93 & 14 & 126 & 1 & -27 & 29 & 219 & 7,55 & 1,43 \\
\hline San Luis & 8 & 17 & 8 & 41 & 0 & -24 & 16 & 58 & 3,62 & 0,38 \\
\hline Otro & 0 & 0 & 1 & 4 & -1 & -4 & 1 & 4 & 4 & 0,02 \\
\hline Subtotal otros & 8 & 17 & 9 & 45 & -1 & -28 & 17 & 62 & 3,64 & 0.40 \\
\hline Total & 667 & 8.210 & 560 & 6.999 & 107 & 1.211 & 1.227 & 15.209 & 12,39 & 100 \\
\hline
\end{tabular}

Fuente: Archivo Histórico de Mendoza, libros de Cargo y Data de 1782, 1783, 1788, 1789, 1793, 1794, 1796, 1797 y 1799.

\section{Los troperos: sus categorías y rutas}

Los troperos se pueden clasificar en cinco categorías, de acuerdo a la intensidad con la que realizaban el oficio: 1) troperos eventuales: realizaron sólo uno o dos viajes; 2) troperos poco frecuentes: efectuaron tres, cuatro o cinco viajes; 3) troperos frecuentes: entre seis y diez travesías; 4) troperos muy frecuentes: de once a diecisiete viajes; 5) troperos principales: desde veinte hasta setenta y cuatro viajes. Cada una de estas modalidades tenía sus propias características (ver Cuadro II). 
Los troperos eventuales formaron un grupo muy numeroso. Fueron 162 sobre un total de 269, lo cual representa el $60,22 \%$ de la muestra. Aunque cada uno hizo pocos viajes, al ser tanta la cantidad de miembros de este grupo, su aporte fue muy relevante. Realizaron 212 travesías, lo cual representa el 17,27\% del total. Y trasladaron casi 2.000 carretas, lo cual representó más del 12\%. En general, sus partidas eran pequeñas: estaban formadas por un promedio de 9,05 carretas, un $25 \%$ por debajo del promedio general.

Los troperos poco frecuentes fueron menos de un tercio del grupo anterior, pero trasladaron más carretas. En efecto, los miembros de este grupo fueron 55, lo cual representa el $20 \%$ de la muestra. Realizaron 202 viajes (16,46\%), es decir, menos que el grupo anterior. Pero sus partidas eran mayores: en promedio llevaban 10,41 unidades en cada partida. Como resultado, transportaron 2.104 carretas, lo cual significa el 13,83\% del total.

Los troperos frecuentes fueron, numéricamente, menos de la mitad del grupo anterior; pero trabajaron tanto que la cantidad de carretas que transportaron fue casi la misma. En efecto, este grupo estuvo integrado por 24 carreteros (9\%), que realizaron 190 viajes $(15 \%)$ y trasladaron 1.825 carretas $(12 \%)$. Sus caravanas eran levemente inferiores a las del grupo anterior, pues tenían un promedio de 9,60 carretas por partida.

Los troperos muy frecuentes fueron todavía menos numerosos que los anteriores, y mucho más laboriosos. El grupo estaba integrado por 16 personas $(6 \%)$ que realizaron 233 viajes $(19 \%)$ mediante los cuales transportaron 3.163 carretas (21\%). Las partidas de este grupo eran muy numerosas pues tenían en promedio 13,57 carretas.

Los troperos principales eran un selecto grupo que realizó el oficio con gran dedicación. Fueron apenas 12 carreteros $(4,46 \%)$, pero en los nueve años registrados efectuaron 406 viajes lo cual representa un tercio del total; además, en cada viaje formaban caravanas muy numerosas, con un promedio de 15,18 carretas por partida. Como resultado, este reducido número de troperos logró llevar 6.198 carretas, equivalentes al 40,55\% del total de la muestra. 


\section{Cuadro II}

Categoría de los troperos

Cantidad de viajes y de carretas transportadas

Mendoza, fines del siglo XVIII

\begin{tabular}{|c|c|c|c|c|c|c|c|c|}
\hline & \multirow{2}{*}{$\begin{array}{l}\text { Cantidad } \\
\text { de viajes }\end{array}$} & \multicolumn{2}{|c|}{ Troperos } & \multicolumn{2}{|c|}{ Partidas } & \multicolumn{2}{|c|}{ Carretas } & \multirow{2}{*}{$\begin{array}{c}\text { Promedio } \\
\mathrm{C} / \mathrm{P}\end{array}$} \\
\hline & & Nro & $\%$ & Nro & $\%$ & nro & $\%$ & \\
\hline \multirow{3}{*}{$\begin{array}{l}\text { Troperos } \\
\text { eventuales }\end{array}$} & 1 & 106 & 39,40 & 106 & 8,63 & 813 & 5,34 & 7,66 \\
\hline & 2 & 53 & 19,70 & 106 & 8,63 & 1106 & 7,27 & 10,43 \\
\hline & Subtotal & 162 & 60,22 & 212 & 17,27 & 1.919 & 12,61 & 9,05 \\
\hline \multirow{4}{*}{$\begin{array}{l}\text { Troperos poco } \\
\text { frecuentes }\end{array}$} & 3 & 24 & 8,92 & 72 & 5,86 & 716 & 4,70 & 9,94 \\
\hline & 4 & 20 & 7,43 & 80 & 6,51 & 818 & 5,37 & 10,22 \\
\hline & 5 & 10 & 3,71 & 50 & 4,07 & 570 & 3,74 & 11,40 \\
\hline & Subtotal & 55 & 20,44 & 202 & 16,46 & 2.104 & 13,83 & 10,41 \\
\hline \multirow{6}{*}{$\begin{array}{l}\text { Troperos } \\
\text { frecuentes }\end{array}$} & 6 & 10 & 3,71 & 60 & 4,88 & 624 & 4,10 & 10,40 \\
\hline & 7 & 5 & 1,85 & 35 & 2,85 & 359 & 2,36 & 10,25 \\
\hline & 8 & 4 & 1,48 & 48 & 3,91 & 319 & 2,09 & 6,64 \\
\hline & 9 & 3 & 1,11 & 27 & 2,20 & 319 & 2,09 & 11,81 \\
\hline & 10 & 2 & 0,74 & 20 & 1,62 & 204 & 1,34 & 10,20 \\
\hline & Subtotal & 24 & 8,92 & 190 & 15,48 & 1.825 & 11,99 & 9,60 \\
\hline \multirow{8}{*}{$\begin{array}{l}\text { Troperos muy } \\
\text { frecuentes }\end{array}$} & 11 & 3 & 1,11 & 33 & 2,68 & 464 & 3,05 & 14,06 \\
\hline & 12 & 1 & 0,37 & 12 & 0,97 & 136 & 0,89 & 11,33 \\
\hline & 13 & 4 & 1,48 & 52 & 4,23 & 708 & 4,65 & 13,61 \\
\hline & 14 & 2 & 0,74 & 28 & 2,28 & 322 & 2,11 & 11,50 \\
\hline & 15 & 5 & 1,85 & 75 & 6,11 & 956 & 6,29 & 12,74 \\
\hline & 16 & 1 & 0,37 & 16 & 1,30 & 334 & 2,19 & 20,80 \\
\hline & 17 & 1 & 0,37 & 17 & 1,38 & 243 & 1,59 & 14,29 \\
\hline & Subtotal & 16 & 5,94 & 233 & 18,98 & 3.163 & 20,79 & 13,57 \\
\hline \multirow{12}{*}{$\begin{array}{l}\text { Troperos } \\
\text { principales }\end{array}$} & 20 & 1 & 0,37 & 20 & 1,62 & 361 & 2,37 & 18,05 \\
\hline & 21 & 2 & 0,74 & 42 & 3,42 & 520 & 3,41 & 12,38 \\
\hline & 22 & 1 & 0,37 & 22 & 1,79 & 323 & 2,12 & 14,68 \\
\hline & 24 & 1 & 0,37 & 24 & 1,95 & 327 & 2,15 & 13,62 \\
\hline & 27 & 1 & 0,37 & 27 & 2,20 & 378 & 2,46 & 14,00 \\
\hline & 28 & 1 & 0,37 & 28 & 2,28 & 387 & 2,54 & 13,82 \\
\hline & 33 & 1 & 0,37 & 33 & 2,68 & 543 & 3,57 & 16,45 \\
\hline & 42 & 1 & 0,37 & 42 & 3,42 & 661 & 4,34 & 15,73 \\
\hline & 43 & 1 & 0,37 & 43 & 3,50 & 725 & 4,76 & 16,86 \\
\hline & 51 & 1 & 0,37 & 51 & 4,15 & 907 & 5,96 & 17,78 \\
\hline & 74 & 1 & 0,37 & 74 & 6,03 & 1.066 & 7,00 & 14,40 \\
\hline & Subtotal & 12 & 4,46 & 406 & 33,08 & 6.198 & 40,55 & 15,18 \\
\hline Total & & 269 & 100 & 1.227 & 100 & 15.209 & 100 & 12,39 \\
\hline
\end{tabular}


Fuente: Archivo Histórico de Mendoza, libros de Cargo y Data de 1782, 1783, 1788, 1789, 1793, 1794, 1796, 1797 y 1799. 
Las cinco categorías de troperos se distinguieron no sólo por la cantidad de viajes realizados y el volumen de sus caravanas. También se diferenciaron por las rutas que con más frecuencia servían. En este sentido, todos tenían algo en común: el mayor número de viajes lo realizaron entre Mendoza y Buenos Aires. La categoría que menos utilizó este camino, lo hizo en casi el $80 \%$ de sus travesías. Otros, en cambio, superaron el $95 \%$ de sus viajes en esta ruta. Además, el aporte de unos y otros a las rutas secundarias fue muy diferente (ver Cuadro III).

Los troperos eventuales realizaron entre Mendoza y Buenos Aires 166 viajes sobre un total de 210 (79\%). Pero en términos relativos, los eventuales fueron los más importantes troperos en la ruta del Litoral: sobre 91 viajes que los troperos de todas las categorías realizaron por esta ruta, los eventuales efectuaron 35, es decir, el 38,4\% de los viajes entre Mendoza y las ciudades del Paraná. También les cupo un papel significativo en el comercio de Mendoza con San Luis, pues, de los 16 viajes efectuados entre ambos puntos, ellos realizaron 4, equivalente al 25\% del total. En cambio, en la ruta de Buenos Aires, los troperos eventuales tuvieron un papel muy menor: sólo efectuaron el 15\% de los servicios entre Mendoza y la capital del Plata.

Los troperos poco frecuentes también tuvieron su principal actividad entre Mendoza y Buenos Aires: en este camino realizaron 171 de sus 202 viajes (84\%). Pero este grupo se destacó, fundamentalmente, en el espacio cuyano. Los troperos poco frecuentes realizaron 9 de los 16 viajes efectuados entre Mendoza y San Luis, lo cual representa el 56,2\% de esa ruta. En segundo lugar, se destaca el papel que cupo a este grupo en las rutas del Litoral: los troperos poco frecuentes efectuaron 18 viajes entre Mendoza y las ciudades del Paraná, lo cual significó el 20\% del total de esa ruta.

Los troperos frecuentes también coincidieron con los demás en concentrar la mayor parte de sus viajes entre Mendoza y Buenos Aires: 145 sobre un total de 174 (83,33\%). Pero en términos relativos, ellos brindaron un aporte significativo en el comercio del Litoral: sobre un total de 91 viajes efectuados entre Mendoza y el Litoral, los troperos frecuentes contribuyeron con $23(25,2 \%)$. También aportaron al comercio cuyano: sobre 16 viajes dentro de este espacio, los frecuentes realizaron $3(18,7 \%)$.

Los troperos muy frecuentes también estuvieron entre Buenos Aires y Mendoza, pero en mayor grado que en las categorías anteriores: ellos realizaron 220 de sus 233 viajes en esa ruta 
$(94,4 \%)$. Muy pocos servicios prestaron fuera de este camino, la mayoría de los cuales se orientó hacia los mercados del Noroeste, sobre todo hacia Córdoba y zona de influencia. Ello les permitió aportar con nueve de los 28 viajes de esa ruta, lo que representa el $32,1 \%$ de la misma.

Los troperos principales tuvieron una orientación muy clara hacia la ruta Mendoza-Buenos Aires. La inmensa mayoría de los troperos de esta categoría, sólo prestaba servicios de transporte entre estas dos ciudades. En esta ruta realizaron 388 viajes sobre un total de 406, lo cual representa el 95,5\%. Fuera de ella, los troperos principales sólo efectuaron 11 viajes entre Mendoza y el Litoral y 7 entre Mendoza y Córdoba. Ninguno de ellos viajó al Tucumán ni sirvió rutas interiores de Cuyo.

\section{Cuadro III}

Categorías de troperos y Rutas comerciales

Mendoza, fines del siglo XVIII

\begin{tabular}{|l|c|c|c|c|c|c|c|c|c|c|c|c|c|}
\hline \multicolumn{1}{|c|}{ Ruta } & \multicolumn{3}{c|}{ Mza-B.Aires } & \multicolumn{3}{c|}{ Mza-Litoral } & \multicolumn{3}{c|}{ Mza-NOA } & \multicolumn{3}{c|}{ Mza-Cuyo } & Total \\
\hline $\begin{array}{l}\text { Categoría } \\
\text { troperos }\end{array}$ & S & E & Subtot. & S & E & Subtot. & S & E & Subtot. & S & E & Subtot. & Total \\
\hline Eventuales & 70 & 96 & 166 & 14 & 21 & 35 & 2 & 3 & 5 & 2 & 2 & 4 & $\mathbf{2 1 0}$ \\
\hline $\begin{array}{l}\text { Poco } \\
\text { frecuentes }\end{array}$ & 78 & 93 & 171 & 8 & 10 & 18 & 2 & 2 & 4 & 5 & 4 & 9 & $\mathbf{2 0 2}$ \\
\hline Frecuentes & 64 & 81 & 145 & 10 & 13 & 23 & 1 & 2 & 3 & 1 & 2 & 3 & 174 \\
\hline $\begin{array}{l}\text { Muy } \\
\text { frecuentes }\end{array}$ & 104 & 116 & 220 & 1 & 3 & 4 & 5 & 4 & 9 & & & & 233 \\
\hline Principales & 184 & 204 & 388 & 5 & 6 & 11 & 3 & 4 & 7 & - & - & - & 406 \\
\hline Total & 500 & 590 & 1090 & $\mathbf{3 8}$ & $\mathbf{5 3}$ & $\mathbf{9 1}$ & $\mathbf{1 3}$ & $\mathbf{1 5}$ & $\mathbf{2 8}$ & $\mathbf{8}$ & $\mathbf{8}$ & $\mathbf{1 6}$ & $\mathbf{1 2 2 5}$ \\
\hline
\end{tabular}

Fuente: Archivo Histórico de Mendoza, libros de Cargo y Data de 1782, 1783, 1788, 1789, 1793, 1794, 1796, 1797 y 1799.

El servicio del flete generó una importante fuente de ingresos para la región. El viaje de una carreta entre Mendoza y Buenos Aires tenía un valor de mercado de entre $\$ 80$ y $\$ 125$. En un documento de 1745 se sostiene que el flete era de $\$ 110$ por carreta. ${ }^{25}$ Hacia fines del siglo XVIII la situación era muy parecida. Dentro

25 Poder dado a Arizmendi para realizar gestiones ante el Virrey del Perú, Mendoza, 27 de febrero de 1745. Archivo Nacional de Chile (en adelante AN), Capitanía General, volumen 800 , fols. 201-202. 
del primer grupo, en 1791 don Pascual Álvarez fletó 17 carretas a $\$ 80$ cada una. ${ }^{26}$ En 1797 Alejo Aldunate realizó una operación de "\$425 por el flete de cinco carretas para carga de frutas a $\$ 80 " .27$ Casi simultáneamente, este mismo empresario realizó un servicio de flete de cinco carretas a Buenos Aires, a un valor de \$100 cada una. ${ }^{28}$ Los troperos principales, a los cuales se confiaban las cargas más valiosas, tenían una tarifa de $\$ 125$. En 1797 , tal como se examina detalladamente más adelante, don Melchor Videla realizó un flete de 31 carretas y media para trasladar armamento y municiones a un costo de $\$ 125$ por carreta, totalizando $\$ 3.936$. En 1800 don Agustín Videla fletó 18 carretas a Buenos Aires por \$3.000, a un valor de $\$ 125$ cada vehículo. 29

Con estos antecedentes se puede estimar que las casi 15.000 carretas que, en los nueve años registrados, recorrieron la ruta Mendoza-Buenos Aires, generaron ingresos por $\$ 1.500 .000$, lo cual implica un promedio anual de $\$ 160.000$. A ello habría que añadir el aporte de las demás rutas, lo cual permitiría rondar los $\$ 170.000$ por año. Este dinero sostenía la vida de los empresarios y peones que realizaban la travesía, y los costos de los proveedores, sobre todo los fabricantes de carretas.

En torno a la carreta surgió también una industria de carpinteros y fabricantes de partes de estos vehículos. En algunos casos, los carpinteros eran actores distintos y especializados, sin mayor contacto con el oficio del tropero. Pero hubo también algunos carreteros, sobre todo los troperos eventuales y poco frecuentes, que también se dedicaban a la carpintería y al negocio de construcción y/o venta de partes de ellas. Un buen ejemplo puede ser el de Juan González. Portugués de nacimiento pero avecindado en Mendoza, González fue carpintero y tropero. Su vida empresaria comenzó con el oficio de la madera; según su relato testamentario, al contraer matrimonio "traje mi herramienta de carpintería que regulo su valor en $\$ 100 " .30$ Posteriormente se dedicó eventualmente al oficio de tropero y realizó varios via-

26 Testamento de Pascual Álvarez, Mendoza, 2 de octubre de 1791. Archivo Histórico de Mendoza (en adelante AHM), Protocolo de Escribanos nº 126 fols. 62.

27 Testamento de Alejo Aldunate, Mendoza, 13 de octubre de 1797. AHM, Protocolo de Escribanos $\mathrm{n}^{\mathrm{O}} 133$ fols. 154 .

28 Testamento de Alejo Aldunate, Mendoza, 13 de octubre de 1797. AHM, Protocolo de Escribanos $\mathrm{n}^{-} 133$ fols. 154 .

29 Testamento de Agustín Videla, Mendoza, 15 de noviembre de 1800. AHM, Protocolo de Escribanos nำ 139, fols. 114

30 Testamento de Juan González, Mendoza, 4 de diciembre de 1804. AHM, Protocolo de Escribanos $\mathrm{n}^{\mathrm{o}} 150$ fols. 169 . 
jes al frente de sus carretas entre Buenos Aires y Mendoza. Si algunos fabricaban y comercializaban carretas completas, otros se especializaron en partes de ellas. Una de estas partes era la llamada "cama", nombre que recibía el "suelo o plano del carro o carreta". ${ }^{31}$ Estos objetos permitían realizar operaciones de compra y venta. Así, por ejemplo, don Agustín Videla, uno de los troperos principales de Mendoza, compró a José Mayorga "28 camas para carreta al precio de 20 reales". ${ }^{32}$ Por su parte don Mariano de la Concha, tropero de la categoría de "poco frecuente", dedicado al flete entre Mendoza y San Luis, también se participó en el comercio de camas de carretas; a Francisco Sáez le vendió dos camas a 22 reales y además, "a Gregorio Santander le presté seis camas".33

\section{Troperos y posición social}

La tarea de los troperos fue ganando en gravitación y ascendente social dentro de la sociedad criolla. Así lo detectaron los investigadores que hicieron mucho trabajo empírico, como Juan Draghi Lucero y Mariano Marcó. Draghi Lucero, reconocido historiador y literato, miembro de la Academia Argentina de Letras, ha ocupado en Mendoza, un lugar parecido al que cupo a Ricardo Palma en Perú; este último elaboró sus Tradiciones Peruanas para entregar, en clave literaria, una recreación de la sociedad tradicional que conoció a través del Archivo General de la Nación (Lima); Lucero, por su parte, volcó largos relevamientos de tradiciones orales y de documentos del Archivo Histórico de Mendoza en obras literarias como los cuentos de Las Mil y una noche argentinas, obra editada por primera vez en 1940. Menos ambicioso desde el punto de vista literario pero muy fuerte en el relevamiento de fuentes originales, el investigador autodidacta Mariano Marcó entregó también sus reflexiones en la introducción de su libro Quién era quién en Mendoza. Tanto Lucero como Marcó han coincidido en destacar el papel de los troperos y sus carretas en la sociedad colonial cuyana.

31 Real Academia de la Lengua Española. Diccionario de la Lengua Española. Madrid: Espasa, 1991, p. 1, 371.

32 Testamento de Agustín Videla, Mendoza, 15 de noviembre de 1800. AHM, Protocolo de Escribanos no 139 fols. 115.

33 Testamento de Mariano de la Concha, Mendoza, 30 de julio de 1794. AHM, Protocolo de Escribanos ํㅜㅅㅣ 130 fols 112 . 
En los cuentos de Draghi Lucero, los dueños de carretas ocupan, por lo general, un lugar en la cúspide de la pirámide socioeconómica de la época. El autor se refiere, por ejemplo, a "un pudiente carretero que comerciaba con Buenos Aires, que había logrado juntar un gran caudal". ${ }^{34}$ En otro momento, un personaje manifestaba sus anhelos de enriquecerse, y lo expresaba justamente, con la imagen del tropero: "yo me apareceré como un rico dueño de carretas. Ricachón y asonsado, hablaré sin ton ni son y andaré ostentando dinero". ${ }^{35} \mathrm{Al}$ describir ropas finas y elegantes, también se apelaba a la imagen del tropero: "Levantó la vista y encontró lujosos roperos, cuyas puertas abiertas dejaban ver trajes que ni los más ricos dueños de carretas usaban". ${ }^{36}$ Draghi Lucero no hizo nada más que plasmar en sus cuentos, las consecuencias que infirió de los testamentos coloniales que había revisado con tanta paciencia. El mismo camino transitó el citado Marcó. Tras realizar un exhaustivo relevamiento de la documentación testamentaria, el autor llegó a la conclusión que las clases dirigentes cuyanas no estaban formadas por terratenientes, sino por los comerciantes y transportistas. El autor señala:

Después de haber leído varios miles de testamentos de esta primera época puedo decir, con total seguridad que las tierras no tenían prácticamente ningún valor, en relación con otras cosas, como por ejemplo un esclavo, o una casa o una carreta [...]. Los verdaderos "ricos" de las primeras épocas fueron los "troperos" es decir, los dueños de tropas, designación ésta que se daba a una formación de doce carretas y un carretón tirados por un mínimo de ocho bueyes hasta un máximo de doce por cada unidad y fue la base de más de una fortuna. ${ }^{37}$

Contrariamente a los mitos creados por las historias estandarizadas, fuertemente influidas por enfoques ideológicos, la historia construida por Marcó sobre la base de referentes empíricos, muestra que la tierra no era un bien escaso y tenía poco valor. En cambio los elementos más dinámicos de la economía eran el comercio y el transporte. O sea, no se daban las condiciones para el surgimiento de una aristocracia rentista, sino que en el Reino de Chile en general y particularmente en Cuyo, el entorno favorecía más las tendencias burguesas. Y ello ponía en foco al sector servicios, co-

34 Lucero, Los tres ladrones. En: Las Mil y una noches..., p. 103.

35 Lucero, Los tres ladrones. En: Las Mil y una noches..., p. 98.

36 Lucero, El negro triángulo. En: Las Mil y una noches..., p. 45.

37 Marcó, Mariano. Quién era quién en Mendoza: índice de los testamentos en actuaciones notariales. Santiago de Chile: edición de autor, 1998, p. 1, 7. 
mo los arrieros y, al menos en la región cuyana, los troperos. Las carretas serían el gran vehículo de integración geográfica y movilidad social.

El ramo del transporte reunía empresarios grandes, medianos y pequeños. Había troperos y arrieros de los tres niveles sociales. Es decir, el tropero no era una clase social, sino un oficio y un tipo de empresa que podía ser realizado por actores de distinta ubicación dentro de la pirámide socioeconómica. Así se desprende tanto del testimonio de los cronistas como de los referentes empíricos obrantes en los archivos y documentos. En efecto, un agudo observador de la época como Concolorcorvo, señaló al respecto:

Los carreteros se dividen regularmente en tres clases. La primera comprende a los hombres más distinguidos de Mendoza, San Juan, Santiago del Estero y Tucumán. Los primeros establecieron este género de trajín para dar expendio en Buenos Aires y Córdoba a los frutos sobrantes de sus haciendas, como vinos, aguardientes, harinas, orejones y otras frutas, fletando el resto de sus buques a pasajeros y particulares, a un precio muy cómodo. Casi siempre se reduce el importe de estos frutos a efectos de la Europa para el gasto de sus casas y particulares comercios; pero como el valor de lo que conducen en veinte carretas se regresa en una o dos, fletan las demás al primer cargador que se presenta por el precio contingente de la más o menos carga y número de carretas. Los segundos son aquellos que tienen menos posibles, y regularmente andan escasas las providencias, con atraso de los viajes; y los terceros son gente de arbitrio. Piden siempre los fletes adelantados y muchas veces al tiempo de la salida se aparece un acreedor que lo detiene, y se ven obligados los cargadores, no solamente a pagar por ellos sino suplir las necesidades del camino y otros contratiempos, por lo que es más conveniente y seguro pagar diez pesos más en cada carreta a los primeros. [...]. Los tucumanos son todos fleteros. ${ }^{38}$

Este rico documento merece analizarse a la luz de los referentes empíricos, pues surgen entonces matices interesantes. En primer lugar, Mendoza, a diferencia de Tucumán, no estaba formada por "todos fleteros"; la actividad más importante de la economía mendocina se hallaba en la vid y el vino: pequeñas propiedades trabajadas en forma muy intensiva. De acuerdo al censo de 1739, sobre un total de 150 vecinos, 105 cultivaban viñas. De todos modos, después de la vitivinicultura, la actividad más importante era el transporte: 12 vecinos poseían tropas de carretas o arrias de mulas.

38 Concolorcorvo. El lazarillo..., p. 72-73. 
Donde sí coinciden plenamente los datos de archivos con las observaciones de Concolorcorvo, es en la presencia de este tipo de empresario en los tres niveles sociales distintos. En Mendoza, sólo 10 vecinos llegaban a los \$10.000. De ellos, tres se dedicaban a las empresas de transporte. El caso más notable era el Maestre de Campo Juan de la Cruz Castillo, cuyos bienes se tasaron en $\$ 32.000$ y lo situaban como el empresario más próspero de Mendoza; junto a él figuraban también como troperos don Fernando de Alvarado (\$15.000) y Juan Gregorio Lemos (\$10.000). De todos modos, los transportistas no pertenecían únicamente a la élite socioeconómica; también se dedicaban a esta actividad sectores de nivel medio, como don Nicolás Gómez y Francisco Corvalán, Sebastián Pérez de Asiain, Gabriel Guevara y José Aguilar cuyos bienes oscilaban entre los \$1.500 y los \$4.000. En una tercera categoría se ubicaban los troperos más modestos, como Manuel Romero y Francisco Santahella, con bienes tasados entre $\$ 500$ y $\$ 700$.

\section{Cuadro IV}

Troperos según el censo

(Mendoza, 1739)

\begin{tabular}{|l|r|l|l|r|}
\hline \multicolumn{1}{|c|}{ Nombre } & Capital & Medios transporte & Otros medios de producción & $\begin{array}{c}\text { Escla- } \\
\text { vos }\end{array}$ \\
\hline Juan de la Cruz Castillo & $\$ 32.000$ & 10 carretas & Bodegas & 24 \\
\hline Fernando de Alvarado & $\$ 15.000$ & Carretas & Estancia, chacras y viñas & 18 \\
\hline Juan Gregorio Lemos & $\$ 10.000$ & Carretas & Estancia, chacra, dos viñas & 8 \\
\hline Nicolás Gómez & $\$ 4.000$ & Carretas & Chacra con viñas & 4 \\
\hline Francisco Corvalán & $\$ 4.000$ & Carretas aviadas & Viñas & 3 \\
\hline Sebastián Pérez de Asiain & $\$ 3.500$ & 10 carretas & Olivares & -- \\
\hline José Aguilar & $\$ 1.500$ & Carretas aviadas & & \\
\hline José de Loyola & $\$ 1.000$ & $\begin{array}{l}\text { Tropa de carretas } \\
\text { aviadas }\end{array}$ & & \\
\hline Lorenzo de Loyola & $\$ 800$ & $\begin{array}{l}\text { Tropa de carretas } \\
\text { aviadas }\end{array}$ & & -- \\
\hline Manuel Romero & $\$ 700$ & Carretas & Viña 1.000 plantas & \\
\hline
\end{tabular}

Fuente: Censo de 1739. Reproducido en Coria, Luis. Evolución Económica de Mendoza en la época colonial. Mendoza: FCE, 1988, p. 297-303. 
El Cuadro IV revela que existía relación entre los transportistas y la industria de la vid y el vino. Buena parte de los empresarios de tropas de carretas poseían, a la vez, viñedos. De una muestra de 42 testamentos de troperos relevados en los Protocolos de Escribanos, nueve $(21,4 \%)$ poseían viñedos y/o bodegas. Sobre 12 testamentos de troperos eventuales, tres de ellos (25\%) poseían viñas: Francisco Sosa declaró poseer "una viña nueva en el terreno que hube de los bienes que quedaron por muerte de mi hermano" ${ }^{39} \mathrm{Al}$ parecer, este tropero trabajaba duro en el cultivo de la viña para hacerla rentable a pesar de la carga que debía pagar cada año por rentas eclesiásticas. Eusebio Videla también cultivaba una viña que recibió por herencia. En su testamento da cuenta de "la viña que heredé de mi padre", la cual "carga una capellanía laical de principal de \$200 de que soy el Patrono con la obligación de mandar celebrar anualmente cinco misas rezadas, en las que he cumplido hasta el presente". ${ }^{40}$ Pedro Martínez señaló como sus bienes "el sitio en que tengo edificada la casa de mi morada", y además "otro sitio ubicado en Alto Godoy en que se halla plantada una majuela y lo demás". Majuela era la forma de llamar a la viña de cepas nuevas. Por su parte, se relevaron 14 testamentos de troperos poco frecuentes, entre los cuales también se registraron tres que eran a la vez viticultores: Felipe Calle, español nacido de Galicia pero avecindado en Mendoza, poseía bodegas y viñedos; la evidencia documental da cuenta de la existencia de ello pues, en su testamento, el empresario dispuso que, para saldar unas deudas, "se echará mano de la cosecha que está en mi bodega". Además, Calle compró viñas que gravó en $\$ 1000$, de los cuales dispuso "caigan sobre ellas $\$ 700$ de principal a réditos de favor del convento de San Agustín y \$300 a favor de Santo Domingo". ${ }^{41}$ Asimismo, Francisco Coria, natural de Chile y vecino también de Mendoza, poseía "diez a doce cepas de poda y otras; y el demás terreno que se encuentra en el sitio, parral de moscatel y todos los demás árboles y plantas que son habidos durante el matrimonio". ${ }^{42}$ Don Nicolás Corvalán poseía una bodega de regulares dimensiones; en su testamento consta que vendió "unos mostos de diezmo". Además,

39 Testamento de Francisco Sosa, Mendoza, 25 de agosto de 1774. AHM, Protocolo de Escribanos $\mathrm{n}^{\circ} 97$ fols. 42 .

40 Testamento de Eusebio Videla, Mendoza, 25 de mayo de 1804. AHM, Protocolo de Escribanos $\mathrm{n}^{-} 149$ fols $43 \mathrm{v}$.

41 Testamento de Felipe Calle, Mendoza, 23 de junio de 1798. AHM, Protocolo de Escribanos no 136 fols. 109 .

42 Testamento de Francisco Coria, Mendoza, 29 de octubre de 1802. AHM, Protocolo de Escribanos n⿳ำ 145 fols. 135 v. 
vendió $60 @$ (2.133 litros) de mosto al precio de 5 reales la @ (35,55 litros) a don Bernardo Sarmiento; y adquirió "doce tinajas bodegueras que tengo en mi poder, que su valor se abonará a cinco reales por @ de buque".43 Una tinaja tenía una capacidad de entre 400 y 700 litros. Con estas vasijas, don Nicolás Corvalán tenía, al menos, una bodega de 6.000 litros de capacidad. Por su parte Agustín Velásquez poseía un cultivo de vides en pleno centro de Mendoza. Su testamento dispuso lo siguiente:

el parral que contiene un sitio de mi dominio que sita en la parte del sur contiguo con la Iglesia Matriz se le dé a mi sobrina Josefa Serrano y todo lo restante del sitio dividido en dos partes, la que mira al zanjón, se le dará a mi sobrina María de los Santos y la otra mitad a los herederos de don Jerónimo Velásquez. ${ }^{44}$

La descripción de esta propiedad da cuenta de su valor. Al encontrarse entre la Iglesia Matriz y el Canal Zanjón, esta viña estaba situada exactamente en el corazón de la ciudad de Mendoza, en la manzana central, frente a la Plaza de Armas. De esta manera se redondea la presencia de la vitivinicultura entre los troperos eventuales y poco frecuentes (que realizaron entre 1 y 5 viajes). El 23\% de los testamentos relevados, pertenecían a empresarios que eran a la vez troperos y viticultores.

El lazo entre el tropero y la industria del vino se debilita a medida que se especializa. Mientras más importancia tenía dentro del ramo del flete, menor era su presencia en el cultivo de la vid y la elaboración del vino. Sobre tres testamentos de troperos frecuentes, ninguno de ellos manifestó la posesión de viñas. Entre los siete testamentos de carreteros muy frecuentes, las viñas aparecieron en dos casos. Por un lado Antonio Lemos, el cual declaró en su testamento que: "sobre mi viña cargan $\$ 300$ a censo redimible". ${ }^{45} \mathrm{El}$ otro es Pascual Álvarez, quien declaró: "un retazo de viña contiguo a lo de Pedro Silva" y "la casa de mi morada con un retazo de viña y lo edificado con árboles". ${ }^{46}$ Por último, entre los troperos principales, sobre seis testamentos relevados, el oficio de viticultor sólo se registró en el caso de Agustín Videla, el cual declaró entre sus bienes "la casa y sitio en donde vivo con lo edificado y plantado con in-

43 Testamento de Nicolás Corvalán, Mendoza, 3 de julio de 1800. AHM, Protocolo de Escribanos no 140 fols. 56 .

44 Testamento de Agustín Velásquez, Mendoza, 2 de marzo de 1799. AHM, Protocolo de Escribanos no 138 fols. 18 v.

45 Testamento de Antonio Lemos, Mendoza, 24 de abril de 1810. AHM, Protocolo de Escribanos no 162 fols. $40 \mathrm{v}$.

46 Testamento de Pascual Álvarez, Mendoza, 2 de octubre de 1791. AHM, Protocolo de Escribanos no 126 fols 61-61 v. 
clusión de la viña y demás árboles". ${ }^{47}$ En total, los troperos más importantes, que realizaban más de 11 viajes, incluyendo frecuentes, muy frecuentes y principales, revelaron la presencia de tres viticultores sobre un total de 16 testamentos relevados, lo cual representa el 18,75\% de la muestra.

Así como muchos troperos eran a la vez viticultores, a la inversa sucedía lo mismo. Muchos viticultores mendocinos tenían a la vez, tropas de carretas. Doña Juana de Lemos, hija del controvertido alcalde Juan de Lemos, al redactar su testamento, mencionó entre sus bienes, una viña de 2.800 plantas y una carreta. 48 Pedro López Bustos poseía viñas, hornos de botijas y dos viñas. ${ }^{49}$ Don Juan de Godoy, uno de los más prósperos viticultores de Mendoza, poseía " 11 carretas, un carretón con su boyada, mulas y demás aperos". ${ }^{50}$ Otro destacado viticultor fue don José Moyano Cabral quien, junto a sus viñas y bodegas, poseía "trece carretas con boyadas y avíos de Buenos Aires". ${ }^{51}$ Este es un caso particularmente interesante porque, en el momento de casarse, Moyano Cabral sólo tenía "un retazo de viña de 3.000 plantas" y las carretas. Con estos medios de producción logró progresar y edificar la bodega. También podemos mencionar a don Clemente Godoy, el mayor viticultor mendocino de la primera mitad del siglo XVIII; junto con sus bodegas y viñedos, en el momento de testar, don Clemente poseía "seis carretas nuevas con sus aperos y 62 bueyes mansos". 52

La necesidad de ubicar el excedente en los mercados rioplatenses fue el móvil principal que llevó a estos grupos a incursionar en el rubro del transporte. Había por lo tanto, un interés directo; las viñas actuaron como motor para impulsar el transporte y el comercio. Estos datos resultan consistentes con el censo de 1803, en el cual se destaca la presencia de viajantes y carpinteros, los cuales se dedicaban, en buena medida, a fabricar carretas. Este censo registró en Mendoza 1023 vecinos con sus respectivas ocu-

47 Testamento de Agustín Videla, Mendoza, 15 de noviembre de 1800. AHM, Protocolo de Escribanos no 139 fols. 114

48 Testamento de Juana Lemos, Mendoza, 10 de julio de 1785. Protocolo de Escribano José Lagos (Mendoza: UNC, 1968, p. 164).

49 Testamento de Pedro López Bustos, Mendoza, 21 de agosto de 1760. AHM, Protocolo de Escribanos no 73, fols. 137 ss.

50 Testamento de Juan de Godoy, Mendoza, 16 de noviembre de 1747. AHM, Protocolo de Escribanos nํㅗㄴ 52 , fols. 138-144.

51 Testamento de José Moyano Cabral, Mendoza, 2 de mayo de 1753. AHM, Protocolo de Escribanos nำ 64 , fols. 29v-30.

52 Testamento de Clemente Godoy, Mendoza, 15 de julio de 1744. AHM, Protocolo de Escribanos $n^{\circ} 50$, fols. 37. 
paciones. Buena parte de ellos eran trabajadores escasamente calificados: 112 no tenían profesión, 167 eran peones y 467 eran labradores. Los 277 restantes tenían oficios especializados: pulperos (47), viajantes (43), carpinteros (38), arrieros (23), comerciantes (20), mercaderes (9), sastres y zapateros (8), herreros y estudiantes (7). Nótese cuáles eran los tres oficios más difundidos que el del arriero en Mendoza: pulperos, viajantes y carpinteros. ${ }^{53}$ Evidentemente, en esta ciudad, después de la vitivinicultura, la principal actividad económica giraba en torno al transporte de tropas de carretas.

Otro indicador de su posición social, además de los testamentos, se encuentra en el tratamiento en términos de "don". El uso de este concepto se remonta a tiempos muy antiguos, cuando estaba reservado para el nombre de figuras religiosas. El "Señor" era el "Dominus", en latín; y el "Don" se utilizó para Jesucristo y los santos. Luego, "en tiempos medievales solamente era usado por los reyes, los ricos-hombres, los obispos y arzobispos. De los primeros los tomaron sus hijos y no se extendió a otras personas". Posteriormente, "el Don se fue introduciendo en las generaciones particulares, ya por derivar de sangre real o por privilegio".54 Así, por ejemplo, cuando Cristóbal Colón y Vasco Da Gama alcanzaron sus proezas geográficas, entre las recompensas que recibieron de los reyes de España y Portugal, respectivamente, figura el derecho a usar el título de "don". Más adelante, en el siglo XVII, el rey Felipe III estipuló que esta distinción podían usarla únicamente personas con determinados rangos como obispos, condes, oidores, ministros y otros altos funcionarios. Con el correr de los años, el uso del "don" se amplió un poco más, pero mantuvo el sentido de distinción y prestigio. Así por ejemplo, "a fines del siglo XVII se solía titular a los dueños de estancias con el Don, pero consta que no lo usaban personalmente en su correspondencia ni en sus actuaciones oficiales". 55

El uso del "don" se fue difundiendo hacia otros grupos sociales. Pero se procuró mantener como un símbolo de distinción y privilegio. Hasta fines del siglo XVIII, sólo podían emplearlo los criollos o mantuanos, no así los mestizos, indios ni esclavos. Esta situación se modificó a fines de dicha centuria por iniciativa del valido Godoy, el cual, influido por las ideas del liberalismo que se

53 Martínez, Historia Económica..., p. 38.

54 Molina, Raúl. Origen del Don. Boletín de la Academia Nacional de la Historia, 38 (1965), p. 298.

55 Ibid., p. 303. 
irradiaban desde Francia, resolvió adaptar las leyes españolas en este tema. Este fue el sentido del Real Decreto de Aranjuez, dictado el 10 de febrero de 1794, por el cual se concedió a las etnias sometidas el derecho de adquirir el título de "don". Algunos autores consideran que esta medida causó un impacto negativo en las élites criollas, que tuvieron allí otro motivo de queja contra la Corona española. Harvey explica este enfoque en los siguientes términos:

Ese gesto a favor del igualitarismo racial horrorizó a los criollos. En abril de 1796, el cabildo de la ciudad de Caracas advirtió alarmado las amenazas de la población local "a pesar de que esa clase es inferior por designio del Autor de la naturaleza". 56

El fuerte impacto causado en la Capitanía General de Venezuela a fines del siglo XVIII por la ampliación legal de la posibilidad de acceder al título de "don" a los grupos subordinados, es un buen reflejo del valor que las clases dirigentes otorgaban a este privilegio. Y esta situación era válida para toda América Latina. La tradición indicaba que sólo podían usar este título honorífico ciertos y determinados grupos de distinción social y económica.

En el marco de la singular importancia que tenía el uso del "don" en los tiempos coloniales, resulta elocuente constatar la frecuencia con que los troperos aparecían dentro de este selecto grupo. En efecto, los libros de las Aduanas, tenidos por los oficiales reales, daban cuenta del reconocimiento que la sociedad de la época tenía con los troperos. Sobre un total de 269 troperos, 59 recibían tratamiento de "don", lo cual representa el $22 \%$ de la muestra.

Esta tendencia se vio consolidada con el tiempo y se ha reflejado en obras de carácter literario. Así por ejemplo cuando Amorín se refiere a un tropero, lo presenta con el prefijo de "Don". Es el caso del tropero don Marcelino Chaves. ${ }^{57}$ Por su parte, Benito Marianetti dedicó una página a don Angelino Arenas, cuyano que logró formar una sólida posición económica a partir de los servicios de transporte terrestre con tracción a sangre. 58

56 Harvey, Robert. Los libertadores: la lucha por la independencia de América Latina, 18101830. Barcelona: Océano, 2002, p. 95.

57 Amorim, Enrique. La carreta. Buenos Aires: Losada, 1952, p. 120.

58 Marianetti, Benito. Semblanzas y Narraciones. Buenos Aires: Anteo, 1975, p. 117-119. Don Angelino Arenas se dedicaba fundamentalmente al transporte de cargas y animales a lomo de mulas. 
El prestigio del tropero, en el sentido de "buen crédito", era una de las bases fundamentales de su negocio. La prosperidad de su empresa dependía, en buena medida, de la confianza que fuera capaz de inspirar en sus proveedores y clientes. Ello le permitía construir redes de crédito en efectivo o bien, de entrega de mercadería al fiado a través de un sistema flexible que facilitaba la circulación de bienes y servicios, a pesar de la crónica falta de circulante. En un próximo artículo se examina con mayor profundidad el papel de los troperos en el crédito.59 Pero aquí lo importante es destacar la importancia que tenía para ellos cuidar el "buen nombre y honor". El resultado fue, por lo general, satisfactorio. Este prestigio les permitió prosperar en los negocios, recibir tratamiento de "don" y hasta contar con el beneplácito de las autoridades de la Corona. En este sentido, los gobernantes llegaron a confiar en los troperos misiones sumamente delicadas, concernientes a la seguridad de la región.

La decisión del Virrey del Río de la Plata, de encargar a los troperos el traslado de armas de guerra desde Chile hasta Buenos Aires para hacer frente a las inminentes invasiones inglesas, es una prueba del notable prestigio alcanzado por este oficio en su época. A fines del siglo XVIII, tras la ruptura entre España e Inglaterra, se hizo cada vez más evidente que los británicos realizarían un ataque directo para tomar la ciudad de Buenos Aires. En este contexto, el Virrey del Río de la Plata, Marqués de Avilés, solicitó ayuda a su par del Perú, don Ambrosio Higgins. Este respondió con toda generosidad y envió una fragata del Callao a Valparaíso con 200 pares de pistolas, 1.500 espadas, 500 quintales de pólvora y 80 quintales de brea y alquitrán. $60 \mathrm{El}$ armamento y las municiones fueron trasladados hasta Santiago de Chile, y de allí era preciso enviarlos por tierra hasta Buenos Aires. Para realizar esta operación, en vez de emplear guardias o soldados, las autoridades optaron por confiarla a arrieros y troperos. Ocho arrieros atravesaron la cordillera con este material estratégico entre diciembre de 1797 y enero de 1798. Una vez en esta ciudad, las cargas fueron confiadas a Melchor Videla, el tropero más experimentado de la región: en los nueve años relevados que se consignan en la primera mitad del presente artículo, consta que

59 Lacoste, Pablo "Los troperos y los orígenes de la burguesía en el Cono Sur de América colonial", Estudos Ibero-Americanos, 2 semestre 2005.

60 Aviso de los 200 pares de pistolas que el virrey del Perú remita al virrey de Buenos Aires, Santiago de Chile, 11 de enero de 1797. AHM, Época Colonial, Carpeta 41, Documento 122; Carpeta 91 Documento 28. 
don Melchor realizó 74 viajes entre Mendoza y Buenos Aires, en los cuales trasladó 1.066 carretas. Para los virreyes de América del Sur, y para el Ministro de la Real Hacienda de Chile, don José Santiago Portales, encargado de la operación, la persona más indicada para cumplir esta tarea era Melchor Videla. Este tropero organizó una caravana con 31 carretas y media para trasladar este material estratégico. La partida salió de Mendoza el 2 de enero y llegó a Buenos Aires el 10 de febrero. La operación tuvo un costo de $\$ 125$ por carreta, totalizando $\$ 3.936$.

El viaje del tropero Melchor Videla a través de las pampas con armamento y munición de guerra tuvo el significado de revelar la alta consideración y confianza que el gremio de los troperos merecía ante las máximas autoridades del Imperio español en América. Téngase en cuenta que la cantidad de armas era suficiente para dotar a buena parte de la tropa veterana del Virreinato del Río de la Plata, integrada por 2.000 efectivos.61 Y los 500 barriles de pólvora que se le confió a Videla eran casi equivalentes a las reservas que tenía la fortaleza de Montevideo, el mayor bastión de seguridad militar del Virreinato, lugar donde "existen en las bóvedas de la nueva fortificación 550 barriles de pólvora de buen servicio".62 Además, este desplazamiento de material de guerra no se hacía como una rutinaria medida de tiempos de paz, sino cuando ya habían estallado las hostilidades entre los dos grandes imperios europeos de ese momento.

61 Beverina, Juan. El Virreinato de las Provincias del Río de la Plata: su organización militar. Buenos Aires: Círculo Militar, 1992, p. 202.

62 Informe de Francisco de Orduña, Montevideo, 31 de diciembre de 1808. Reproducido en Beverina, El virreinato..., p. 400-401. 